\title{
Sciendo
}

DOI: $10.2478 /$ jolace-2019-0004

\section{PhD graduates at Czech Universities: the Account of their Study, Postdoc Options and Job Ambitions}

\author{
Adriana Wiegerová \\ Faculty of Humanities, Thomas Bata University in Zlín, Czech Republic \\ wiegerova@utb.cz
}

\begin{abstract}
The aim of the paper is to describe the PhD study and after graduation situation of graduates of Czech universities who completed their programme between $2010-2017$. The first phase of the investigation was a quantitative study of a representative sample of Czech $\mathrm{PhD}$ graduates that aimed at revealing details of their study and after-graduation opportunities and careers. The second phase of the investigation was a qualitative study of a small sample aimed at understanding the reasons of young people to pursue a $\mathrm{PhD}$ programme at a university, to reveal academic, social and personal factors that influenced their decision to complete the PhD study and start an employment at a university.
\end{abstract}

Key words: academic career, PhD study graduate, postdoc

\section{Introduction}

Educational research has accumulated rich data about the studies and lives of doctoral students (Davis, 2013; Gardner, 2007; McAlpine, Jazvac-Martek \& Hopwood, 2009; Turner \& McAlpine, 2011; Jaraim \& Kahl, D., 2012; Neusar, Charvát et al., 2012; Vekkaila, Pyhältö \& Lonka, 2013, Kosová, 2013). A wealth of information has also been collected about postdoctoral years (Melin, 2005; Mareš, 2013, Åkerlind, 2008). However, data concerning the professional paths of university teachers in the Czech Republic after completion of a doctorate are scarce. Some findings were published by Šed'ová et al. (2016), but they primarily concentrated on the quality of teaching and self-concept of young teachers at one Czech university. This investigation serves to extend the knowledge about doctoral graduates providing both a picture of a representative sample of graduates and a detailed portrayal of o small sample of them.

\section{Research aims}

The paper is aimed at describing the PhD study and after graduation situation of graduates of Czech universities who completed their programme between $2010-2017$. 
The first phase of the investigation was a quantitative study of a representative sample of Czech PhD graduates that aimed at revealing details of their study and after-graduation opportunities and careers.

The second phase of the investigation was a qualitative study of a small sample aimed at understanding the reasons of young people to pursue a $\mathrm{PhD}$ programme at a university, to reveal academic, social and personal factors that influenced their decision to complete the PhD study and start an employment at a university. Overall, the two phases of the investigation describe the developmental phases in academic and occupational careers of young university graduates, including the external and internal factors that determined their professional growth in the Czech Republic.

\section{Research desing}

In the first phase of the investigation the aim was to obtain a broad picture of $\mathrm{PhD}$ graduates in every discipline offered at Czech universities. We wanted to learn about the duration of the study, option for study abroad, and postgraduation careers. The respondents are a representative sample of Czech university $\mathrm{PhD}$ graduates who completed their $\mathrm{PhD}$ programme at Czech universities between 2010 - 2017 and then entered the labour market $(\mathrm{N}=302)$. The demographic breakdown of the sample is displayed in Table 1.

Table 1: Three variables of the representative sample of $\mathrm{PhD}$ graduates sample $(\mathrm{N}=304)$

\begin{tabular}{|l|l|l|}
\hline Age & $\mathrm{M}=33.6 ;$ SD 2.9 & Range 28 - 50 \\
\hline Nationality & Czech 85.1\% & Slovak 14.6\% \\
\hline Branch of study & Sciences $57.3 \%$ & Humanities $42.7 \%$ \\
\hline
\end{tabular}

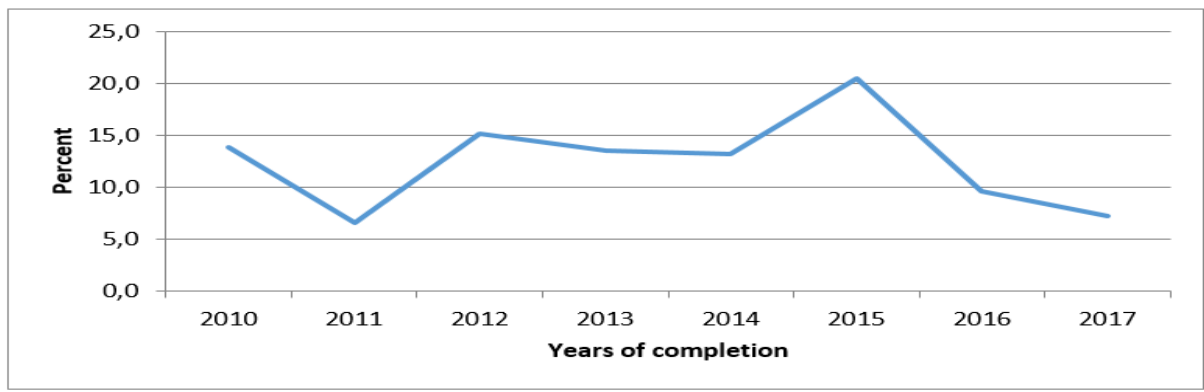

Fig. 1: The number of PhD students graduating between 2010 and 2017

$(\mathrm{N}=304)$ 
The respondents' branch of PhD study was divided into two broad categories. Humanities include arts, linguistics, sociology, history, psychology, education, Bible studies, international relations, and economics. Sciences include chemistry, physics, technology, metallurgy, building, transportation, mathematics, architecture, and computer science.

In the second phase of the investigation (2013-2016) qualitative data were gathered about PhD graduates (see Wiegerová, 2016) explaining the prolongation of their PhD programme and description of their jobs at a university. The sample consisted of ten participants who were employed at universities in the Czech Republic at the time of the study. They were seven females and three males, belonging to the same generation of university teachers. They shared these characteristics:

a) Age (between 27 and 40)

b) PhDs in pedagogy

c) Employment contract at a university in the Czech Republic

d) Commitment to sharing their academic and vocational experience with the researcher.

e) Provision of oral consent with participation in the study.

At the time of the investigation, the study participants worked at the university a maximum of five years. They were contracted for the position of a university teacher. Thus, this sample consists of university teachers who have already been integrated into the professional community and have been published. In the recruitment process, I invited fifteen university teachers to participate in the study. However, only ten consented. These constitute the sample. The reasons for refusal was lack of time or some unclearly-stated concerns about privacy. The following sections contain individual characteristics of the study participants, starting with the three men.

\section{Methods}

\section{Questionnaire}

In the first phase of this investigation a questionnaire was used that consisted of closed and open questions. They concerned the age and nationality of the graduates, the year of completion of the PhD programme, duration of the study, $\mathrm{PhD}$ study branch, interest in a postdoc position, participation in a mobility programme abroad exceeding two months, and the current employment. The respondents were addressed individually by trained survey specialists, questions were read to them and their answers were recorded and quantitatively analysed. 


\section{In-depth interview}

The research method used in the second phase of the investigation was indepth interview administered by the authoress. In the preparatory phase, the content frame of the interview was constituted. The frame consisted of topics as follows:

- motives to study for a doctorate

- views of university teacher responsibilities

- identification with the position of a university teacher

- identification with the position of a researcher

- views of the next phases of the professional career.

At the beginning of the field data collection, the participants provided informed consent. The purpose of the study and the circumstances were explained to them, including how their anonymity would be protected by the researcher. The place and the time of interview was negotiated.

The interview consisted of a set of questions generated from the thematic domains. Many questions emerged during the interview. The first few interviews convinced me of the relevance of the thematic domains. Gradually, the questions became more aim-directed and clearer. My strategy was to let the interviewee talk continuously, as interruption-free as possible.

Only two identical questions were posed to all participants, the first and the last. The intention of the first question was to draw the participant into the interview. The question was, "How do you recall your doctoral studies?" It elicited recollections and thus served as an efficient stimulator. The last question, "What will you recall tonight about our meeting?", aimed at participant self-reflection.

A specific feature of the interview was that the participants themselves have had experience with empirical research, so they critically followed my way of managing the interview. They observed my verbal and nonverbal communications and probably evaluated them. Being aware of this "participatory monitoring" brought a certain burden to the conduct of my interview.

Another specific feature was that the participants themselves posed questions to me. This also may be attributed to the research experience of the participants. For instance, they frequently asked a question like, "How was this in your case?". This can be interpreted as testing the researcher and as an effort to gain a stronger position in the conversation. Sometimes, the participants posed questions because they were unable to answer my questions. Interestingly, such questions were only asked by women.

The interviews generally took place at the participants' "home universities" and in their offices, to increase their comfort. There were two exceptions: two male participants agreed to be interviewed outside of their workplaces, but still at a 
university, a relatively familiar environment. The duration of the interviews was dictated by time constraints of the participants, albeit with a minimum requirement of one hour.

Each interview was recorded on two voice recorders, which minimised losses in case of the failure of one recorder. Transcripts were made from both recordings by two assistants, and the two versions of the transcripts were compared for accuracy. Discrepancies were resolved in discussion. As a result, a single transcript was made from the two.

To begin with, I organized an unrecorded informal initial conversation with each participant, during which I explained the purpose of the study. The participants were encouraged to ask questions, which they did. The questions concerned, for instance, the implementation of the research findings. The participants were assured that no personal information would be misused. Privacy was protected by anonymising the transcripts.

After the formal interview, an off-record conversation usually took place in which the participants asked more questions usually related to my personal experience with a PhD programme or my work at the university. This part of the session took as long as one hour. For both the participants and myself, emotions accumulated during the interview, and were necessary to release. The postinterview, off-record conversation served this purpose.

There are several styles of conducting an interview. As far as this study is concerned, I would refer to my style as a listening colleague.

After the completion of the interview sessions, transcripts of the interviews were created. A transcript is a conversion of an oral record into written form. This conversion is a pragmatic matter. Analysis of transcripts is more comfortable than that of a sound recording. In the written text, one can easier locate necessary segments, and the written format enables the coding procedure and the inclusion of the researcher's memos.

Transcripts are prepared according to rules which constitute a system that guarantees the uniform conversion of all records into the written form. Thus, transcription constitutes a reliable tool for data analysis. There exists a variety of transcription systems used in qualitative investigations, differing by approach to data and degree of detail. The selection of the system is determined by the aims of the investigation and the researcher's theoretical perspective. For instance, in conversation analysis (Jefferson, 2004), researchers use a narrow transcription, which captures both the verbal content of the speech and paralinguistic features such as emphasis, pitch, length of pauses (measured in tenth of seconds), etc. Many qualitative researchers do not need such a minute transcript; rather they concentrate on the content of speech. This was also my case. The transcription rules used in my study were as follows: accurate verbatim verbal content of the participants and the researcher, including incomplete words and "repairs", 
expressions of agreement ("mhm") and hesitation ("ehm"), pauses longer than 3 sec. ("..."), laughter ("laugh"), incomprehensible segments caused by mispronunciation, external noise, etc. ("incomprehensible"). These transcription rules proved satisfactory and fully functional for the analysis.

The analysis was based on a recursive reading of transcripts, through which I gradually immersed myself into the thinking and opinions of the participants and created a global view of them, attempting to understand the interview as a compact whole (Pope et al., 2000). I made frequent interpretative memos, highlighted important segments and looked for relationships among them. Gradually, I constructed a memos system for the next phase of data analysis (Miles, Huberman \& Saldaña, 2014, p. 93).

\section{Results}

\section{Duration of the PhD study}

The first question in the quantitative phase of the investigation concerned the duration of the respondents' PhD study. Fig. 2 shows that a five year long study predominated in the sample. Nearly half of the respondents needed 10 semesters to complete it. About one-third of the sample exceeded the recommended duration of study by one year and a small portion of respondents studied as long as eight years.

The standard length of PhD study in the Czech Republic is four years. Earlier it was even shorter - three years. However, this proved to be an extremely short period, resulting in failure to complete the programme by students. Our data show that only $13.6 \%$ of $\mathrm{PhD}$ students were able to complete the programme in four years.

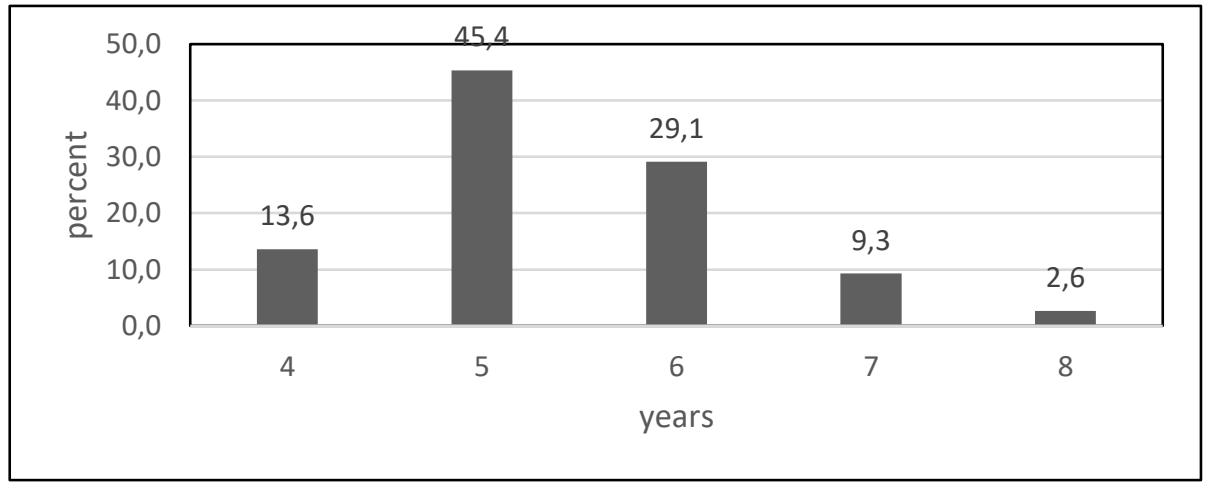

Fig. 2: Duration of the respondents' PhD study $(\mathrm{N}=302)$ 
On the other hand, the majority of PhD students extended their study by one or two years. In contrast to assumptions, the four years long study was not typical for full time students; many of them studied longer.

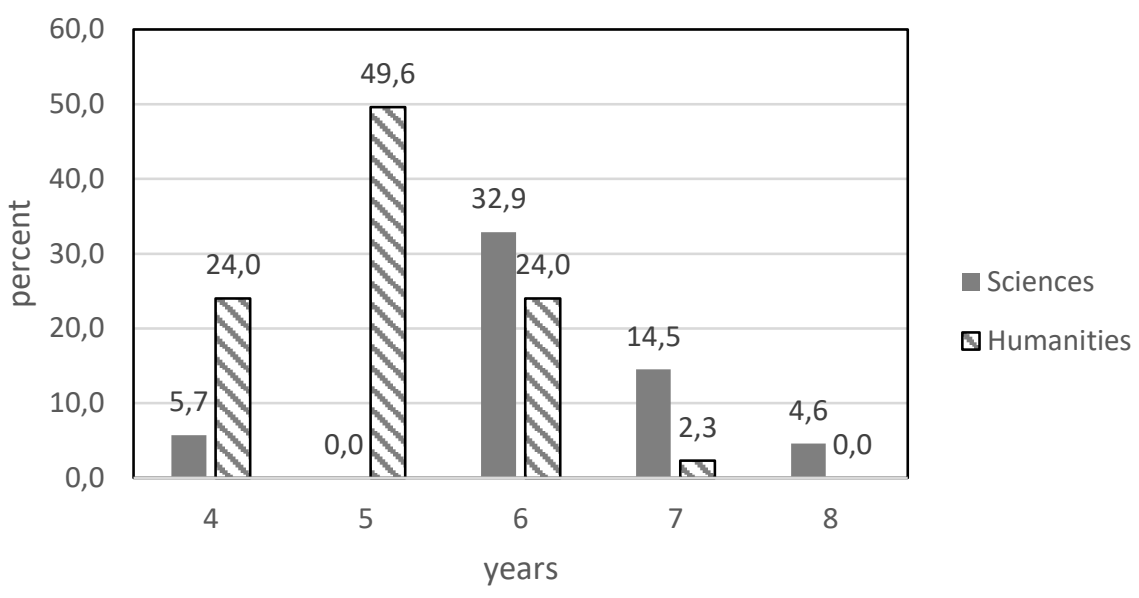

Fig. 3: Duration of the respondents' PhD study according to the study branches $(\mathrm{N}=302)$

Universities in the Czech Republic have a varied attitude towards extension of the PhD study beyond the prescribed period. Many of them permit the extension as long as seven years, others not. The prolongation is a logical step if the university wants to have graduated doctoral students. For instance, Faculty of Arts in Brno typically allows to extend the study. During the last ten years only two students completed their programme within four year, others extended their studies up to double of this figure (Pol, 2018).

A more detailed picture of the duration of the $\mathrm{PhD}$ study can be obtained if the respondents are grouped into the two large branches of study. Fig 3 shows that most of the students in sciences completed their PhD programme in six years, while students in humanities in five years. There were minimum students who graduated after 6 or 7 years, and none of them studied as long as eight years.

\section{Reasons of the PhD study prolongation}

The reasons of the prolonged duration of $\mathrm{PhD}$ studies, other than the specialisation of the $\mathrm{PhD}$ programme, was the main finding of the qualitative part of the investigation. The reasons, which were identified, were both academic, occupational and personal: 
- High academic demands of the PhD programme.

- Weak or no knowledge of a foreign language - a prerequisite to study foreign literature.

- Study abroad (Students opt for an international study that, on one hand make them possible to acquire new competences and experiences, on the other hand, it prolongs it.)

- Family situation (motherly responsibilities of female students).

- Taking a job (it is not rare that full-time doctoral students take an employment to improve their financial matters).

- Establishing a family (this factor either prolongs the study or forces the student to transfer to part-time study).

- Workload of the students in part-time programme. They have problems to harmonize employment and study requirement

- Scientific maturation (those students who extended their study claimed that they needed time to mature for scientific work).

A fine-grained analysis in the qualitative part of the investigation identified two groups of students according to their academic routes (Table 2). Group one consists of 6 students, group two had 4 students. (All participants focused their $\mathrm{PhD}$ in Educational Studies.) The two groups differed in the length of the $\mathrm{PhD}$ study, age of its completion, motivation to pursue the study, effort to gain a stable position at a university (equals to associate professorship) or strong self-demands.

\begin{tabular}{|l|l|}
\hline First group = academic route No. 1 & $\begin{array}{l}\text { Second group = academic route } \\
\text { No. } 2\end{array}$ \\
\hline $\begin{array}{l}\text { Rapid pace of PhD studies; usual } \\
\text { duration of 4 years. }\end{array}$ & $\begin{array}{l}\text { Slower pace of PhD studies, usual } \\
\text { duration of 5-7 years. }\end{array}$ \\
\hline Age of completion, 25-27. & Age of completion, 30+ \\
\hline $\begin{array}{l}\text { Naïve conceptualisation of PhD } \\
\text { studies; strong motivation for earning } \\
\text { an associate professorship. }\end{array}$ & $\begin{array}{l}\text { Strong motivation for research } \\
\text { projects. }\end{array}$ \\
\hline $\begin{array}{l}\text { Effort to ease the route to associate } \\
\text { professorship. }\end{array}$ & Higher self-demands. \\
\hline
\end{tabular}

Table 2: Professional routes of the two groups of PhD graduates (Wiegerová, 2016)

\section{Study abroad}

University students are offered mobility programmes abroad, such as Erasmus+. These programmes generally aim to increase their research competence in the particular field and develop a better command of a foreign language. Though these students often witness barriers and obstacles during their 
study outside the Czech Republic, in general, they evaluate this study and research experience favourably. Students in PhD programmes - in addition to those in $\mathrm{Bc}$ and Mgr programmes - have a priority to engage in international research, including becoming members of research teams and thus expand their knowledge and skills atop of those learned at their home university.

It was a surprising finding that as many as $65.2 \%$ of students in the representative sample of doctoral graduates of the present investigation did not take part in international study visits. It was also a surprise to find out that $\mathrm{PhD}$ students in humanities significantly outperformed those in sciences in taking the opportunity of study abroad for a period of two months or longer. As many as 41.8 $\%$ of the respondents spent a period within their study at another university, mostly in a foreign country. The students of sciences made use of this opportunity less frequently, only $29.5 \%$ of them studied abroad.

One of the obstacles that prevents a student to study abroad is weak command of English. This language has become a primary means of scientific communication and its command becomes a prerequisite to doing research. Therefore, universities provide courses to remove the obstacle that a student has little or no command of English (Pokrivčáková, 2017; Králová, 2018). However, it takes a longer period of time for a student to acquire at least the reading knowledge of the language. The courses are difficult for learners with no English basics.

Since the Czech University Law of 2017, PhD students are obliged to take an international study for a certain period of time. The study can be substituted, however, by taking part in conferences. Therefore, the universities offer the students mobility programmes as well as provide them English courses.

\section{A job at a university}

Though a doctoral degree is an entry ticket to a wide range of employment, receiving a job at a university was the target of most of the $\mathrm{PhD}$ graduates. As many as $68.2 \%$ of the respondents in sciences and $63.6 \%$ respondents in humanities were offered a job at a Czech university - and accepted it. They became university teachers, and thus set on a route in the hierarchy of university positions.

As documented by the participants' accounts in the qualitative part of the investigation, occupational adaptation and social identification at the workplace are closely connected with the university culture. The university culture, i.e., its traditions, symbols, and values, are vital to academic wellbeing because it provides stability and continuity. An institution's culture includes a complex structure of relationships, phenomena and everyday events, which gradually evolve and change. The university culture is demonstrated in its daily way of life, and it clearly distinguishes those who belong to it and those who do not. Experiencing a culture daily means sharing its ingredients and having a sense of belonging to the cultural community. 
According to anthropologist White (1949), a culture is a system of symbols. Symbols are signs that are carriers of meanings in a given community. Symbols constitute an image of the institution, though culture has many more elements than symbols. For instance, Folch and Ion (2009, p. 146) delineate the university culture as a sum of convictions, values, behaviour, norms and symbols related to the following components: management, finances, research, instructional methods, teachers' profiles, evaluation, IT and the territorial growth of a university.

Prior to taking a job at a university, the study participants had a primary conceptualisation of the institution. For them, a university was an institution symbolized by the following:

- intelligence - "it is a place for intelligence" (F7) ${ }^{1}$,

- silence - "it is a space where nobody is shouting, where pupils do not rush along corridors" (F1),

- possession of time - "it is a place where I am the owner of my time" (F6),

- collegiality - "it is a place where I have colleagues and collaborators with whom I can discuss matters" (M1),

- career growth - "It is a place where I can grow professionally" (M2).

Each of these quotes indicates an element of culture that the participants believed in when they were considering joining a university. The symbol intelligence represents a belief that a university is a place where there are people whose life goals are the support of education and the creation of new values. The symbol silence signifies a desire for calmness for work, absent of shouting children. The symbol possession of time signifies a belief that time is an asset that can be managed, e.g., one can keep writing as long as desired. The symbol collegiality signifies that a university is a place of mutual understanding and cooperation. The symbol career growth signifies a belief that a university is a place where the behaviour and actions of people are aimed at professional development and work satisfaction. It is a place where the material and financial conditions are good (though not superior), allowing freedom of spirit and cooperation in creating new values.

Traditions and history also buttress the university culture. The study participants were employed at universities with the following traditions:

1. Universities that have relevant historical traditions, sometimes referred to as "stone-built universities" (M1, M2, M3, F4, F5).

2. Universities that have little-to-no historical traditions, sometimes called regional or "redbrick" universities (F1, F2F, F3, F6, F7).

1 The interview participansts were coded $\mathrm{F}$ or $\mathrm{M}$ (female or male). The number specifies individual participants. 
One important conclusion can be derived from the participants' accounts. If the participants graduated from a full-time study programme at a brick-and-mortar university, then they received a job at this university immediately upon completion of their doctorate. Typically, they were offered a job while still studying, which meant that their adaptation to the university milieu was quicker than that of PhD graduates who took jobs after the completion of their studies. They knew the norms and rules of a university, so they transferred from full-time to part-time study. The cost of this job was the prolongation of their study. Their occupational adaptation and social identification was quick, and it influenced the course of their doctoral studies.

A half of a year into my doctoral studies, I went to an interview for a job at the department. I became a university teacher. Therefore, I switched to part-time study. Consequently, I became a member of the department from the very beginning of my doctoral studies and I had responsibilities as others had. I had a lot of tasks, and they started to accumulate. I was responsible for outreach courses, which I enjoyed, and I also did things like ERASMUS visit coordination, timetable management and the like. In addition, I had to work on my PhD. This was very demanding, it attacked my brain. One had to concentrate to manage the role of a teacher, then the role of an administrator. Only then did I have time for my PhD. (M1)

My studies lasted seven years. But during it I learned to think more thoroughly, I changed my original doctoral research project. Incidentally, I came across people who inspired me. (M2)

Those study participants who started their teaching careers at a regional or "redbrick" university first completed their PhDs and then went to the job interview, which they won. Frequently, these participants studied part-time.

I was waiting for an opportunity to apply for a job at a university. (F2)

I wanted to quit teaching at the [primary or secondary] school, so a PhD was an entry ticket to the university. (F2)

The job they received after their PhD was the first occupation in their career. In academia, they came across many factors they had to take into consideration.

Their conceptualisation of a university deviated from reality because they were unable to get a real picture of it (of its culture) in the course of their doctoral studies. The part-time study distorted the reality of a university.

Such findings are similar to those of Folch and Ion (2009) in their study undertaken in Catalonia. They describe two levels of the culture of a university. The first level concerns the functioning of a university as a whole. The structure of a university is determined by historical and regional traditions. In turn, these traditions are affected by political and institutional factors. The second level of the university culture is the creation of its values and supporting its role as a research 
institution. However, research is separate from instruction. A researcher and a teacher do not constitute an integrated whole. Similar ideas could be identified in the accounts of this study's participants.

The participants explained that teaching and organizational tasks dominated their initial years at the university. Researching was suppressed, while teaching was given preference. This picture was identical both in participants in stone-built and red brick universities.

On completion of my master's I started the doctoral programme chiefly because there was no one to teach sociological courses. As a full-time student, I could not teach 10 lessons per week so I transferred to part-time study. All responsibilities began to accumulate: workplace tasks, accreditation documents, teaching and the like. It helped me to mature, but there was no time for doing research. It did not change after completion of the doctoral programme. I do not teach less, and organisational tasks have not decreased. Although my research has been postponed, thanks to more favourable circumstances I would actually have time for it. (M2)

A university culture is also formed via teamwork. Collegiality can be deciphered in official university documents, but it also appears in a department's climate. The participants reported that the need for teamwork and the search for human interaction were important components of their workplace identification.

Sorry to say, if the climate is inappropriate, the work performance decreases. (M3)

Workplace climate is created by a pressure-free environment. (M1)

Team work helps me, so I often sit with colleagues at the office and we think, speculate, discuss things, and write... For me it is vital that next to me there is a friendly person. (F1)

Teamwork strongly supports the university culture. At those universities where teamwork is well established, the employees take it for granted and, in fact, they do not scrutinize it. A high level of identification with an institution can be conceived as a result of a melting pot of values, traditions and practices.

The work achievements of employees are determined by understanding the colleagues and their work cooperation. This was confirmed by Simplicio (2012), who claims that it is appropriate if young teachers learn to communicate effectively with older colleagues who already possess experiences and hold positions. They must also learn to effectively interact with colleagues to ensure that the mission of the institution is fulfilled and that students' needs are properly met. Simplicio refers to experienced academicians as "guardians of the culture" who work to maintain it and its delicate balance. "They are the keepers of the traditions and protectors of the history and culture of the institution. These individuals include veteran faculty members, entrenched staff members, and 
others with longevity and seniority. They stand watch over the status quo, they begrudgingly allow only the most necessary of changes, and they usher in newcomers and indoctrinate them into the field" (Simplicio, 2012, p. 237).

In order to be successful within a university, a $\mathrm{PhD}$ graduate must learn to efficiently work with individuals, whose standing often gives them instant credibility within the professional community. If a university lacks these individuals, young people cannot observe important social models that help them to learn the academic culture.

Social isolation is the reverse of culture. Isolation can be perceived from two different perspectives, as a positive or as a negative characteristic. The study participants reported that their participation at conferences organized in the Czech Republic was rated low by the Czech Ministry of Education, therefore they avoided them. By this they isolated themselves from the professional community. ${ }^{2}$

Currently they make us isolated individuals. Unfortunately, the virtual environment has begun to be used also in academia. (M3)

Therefore, the participants much appreciated any chance of interaction with members of the professional community at conferences - if such chances existed. They considered such interactions important for their personal growth. They felt that written communication cannot substitute for face-to-face contact.

I wish there was a duty to participate at conferences. I am very grateful I have had such opportunity because it forced me to cultivate both my oral and written communication. I was learning how to cope with stress. (F6)

The opposite pole of conceiving social isolation is appreciating it. Solitude is needed if an individual works on studies and articles. The participants looked for undisturbed opportunities to work. In this respect, social isolation is a favourable matter.

When I am writing a text I want to be on my own and I seek solitude. Otherwise, I will fail. Right now, I received a review of my manuscript and I have to revise it. I am working on it vigorously. But occasionally I feel that events bother me, they interfere with my privacy. On the other hand, I cannot avoid it. (F1)

Folch and Ion (2009) conceive isolation as a kind of manifestation of freedom. Solitude is a precondition of teachers' activities. It is a necessary element for concentration on work tasks.

2 Participation at Czech conferences brings few credit points, thus little money to a university, in contrast to international conferences. 
When I came to the university I loved to teach. But now it has changed a little. I need peace for writing. I am scared when students come and go, and this bothers me. I wish I had more freedom for quiet writing. (F2)

Social isolation, then, can be both a prison and a place of asylum. Sometimes teachers separate themselves from students and immerse themselves in their thoughts. Others literally fight for contacts with colleagues and for cooperation in order to be productive.

\section{Postdoc ambitions}

The present investigation was also targeted on postdoc ambitions of $\mathrm{PhD}$ graduates. After the student received the $\mathrm{PhD}$ diploma, he/she may decide about a next step in the professional career. One of the routes to be a highly qualified researcher is to take a postdoc position at a university. As many as $83.3 \%$ graduates in sciences and $81.4 \%$ in humanities in our sample had an ambition to take a postdoc position - but only a small portion of them have this ambition fulfilled. Postdoc positions are scarcely offered to $\mathrm{PhD}$ graduates by universities or research institutes (like academy of sciences). Interestingly, no respondent had an ambition to take a postdoc position abroad.

Graduates who did not become academics started jobs offered in the labour market. Graduates in sciences listed 47 jobs, mostly in private businesses, ranking from employees to managers. Those who completed the PhD programme in humanities listed 36 different jobs as different as business analyst, financial manager, primary school teacher, press secretary, or senior citizens home manager. Only one graduate stated he is unemployed ( $\mathrm{PhD}$ in archaeology).

\section{Conclusion}

The interviews support the finding that the main reason to enter into the doctoral programme was not to be become teachers or researchers but to get a job at a university. A PhD was an entry ticket to employment in academia (Wiegerová, 2016).

Why was a university considering their career target? As it appeared in the study participants' accounts, the key reason was the professional status they gained by becoming university teachers, a position much valued within their social setting (family, friends, and the community). The professional status was more appreciated than the salary, which is, by the way, not high if compared to other highly qualified employees in the Czech Republic. Furthermore, they witnessed that a university offered them intellectual liberty, spiritual freedom and opportunity for self-improvement. The latter was not associated with knowledge and skills to conduct research. A researcher was not described as a career target.

Another point worth discussing is the position of postdocs. Generally speaking, a postdoctoral position is a temporary post in which a $\mathrm{PhD}$ graduate receives 
continuing training in research. A postdoc position is a transitional post to a permanent career in academia or other higher institution. In contrast to the science, Czech universities offer very few postdoc positions in pedagogy. Postdoctoral practice and training provide a young researcher developmental opportunities. This requires that university has specialists who concentrate on supporting the professional development. Many universities in other countries nominate postdoctoral trainees and offer a special programme concentrating on those who guide the postdoc throughout their programme. A good example is the University of Alabama at Birmingham (Lorden \& Matalon, 2002, p. 49).

\section{References}

AKERLIND, G. S. (2008). Growing and developing as a university researcher. Higher Education, 55(2), 241-254.

DAVIS, G. (2013). Advising and Supervising Doctoral Students: Lessons I Have Learned. University of Minnesota. Retrieved from http://misrc/umn.edu/workingpapers/fullpapers/2004/0412_052404.pdf.

FOLCH, M. T. \& ION, G. (2009). Analysing the organizational culture of universities: Two models. Higher Education in Europe, 34(1), 143-154.

GARDNER, S. K. (2007). "I heard it through the grapevine": Doctoral student socialization in chemistry and history. Higher Education, 54(5), 723-740.

JARAIM, D. \& KAHL, D.H. (2012). Navigating the doctoral experience: The role of social support in successful degree completion. International Journal of Doctoral Studies, 54(7), 311-329.

JEFFERSON, G. (2004). Glossary of transcript symbols with an introduction. Pragmatics and Beyond New Series, 125, pp. 13-34.

KOSOVÁ, B. (2013). Vysokoškolské vzdelávanie učitel’ov na Slovensku. Pedagogika, 63(4), 485-500.

KRÁLOVÁ, Z. \& MALÁ, E. (2018). Teaching foreign languages in Slovakia (1918 2018). XLinguae, 11(4), 11-21 ISSN 1337-8384.

LORDEN, J. F. \& MATALON, S. (2002). Easing the perils of the post-doctoral years a call for institutional attention. Change, 34(1), 44-49.

MAREŠ, J. (2013). Neviditelná skupina aneb co s postdoktorandy? Pedagogická orientace, 23(1), 5-26.

McALPINE, L., JAZVAC-MARTEK, M., \& HOPWOOD, N. (2009). Doctoral student experience in Education: Activities and difficulties influencing identity development. Intenational Journal for Researcher Development, 1(1), 97-109.

MELIN, G. (2005). The dark side of mobility: negative experiences of doing a postdoc period abroad. Research Evaluation, 14(3), 229-237.

MILES, M. B., HUBERMAN, A. M., \& SALDANA, J. (2014). Qualitative data analysis. 3rd edition, Los Angeles: SAGE. 
NEUSAR, A., CHARVÁT, M. et al. (2012). PhD existence v oboru psychologie v České republice a na Slovensku. Olomouc: Filozofická fakulta Univerzity Palackého.

POL. M. (2018). Doktorandi na univerzitách. Zlín: UTB - prednáška pre študentov $\mathrm{v}$ rámci konferencie Fórum mladých výskumníkov.

POKRIVČÁKOVÁ, S. (2017). Evaluating CD ROMs for Pre-Primary English Courses in the Czech Republic and Slovakia. Language, Literature and Culture in Education, 4(2), pp. 3-23.

POPE, C., ZIELBAD, S., \& MAYS, N. (2000). Qualitative research in health care: Analysing qualitative data. British Medical Journal, 320(7227), 114-116.

SIMPLICIO, J. (2012). The university culture. Education, 133(2), 336-339.

ŠEĎOVÁ, K., ŠVAŘÍČEK, R., SEDLÁČKOVÁ, J., ČEJKOVÁ, I., ŠMARDOVÁ, A., NOVOTNÝ, P., \& ZOUNEK, J. (2016). Pojetí výuky a profesní identita začínajících vysokoškolských učitelů. Studia paedagogica, 21(1), 9-34.

TURNER, G. \& MCALPINE, L. (2011). Doctoral experience as researcher preparation: activities, passion, status. International Journal for Researcher Development, 2(1), 46-60.

VEKKAILA, J., PYHÄLTÖ, K., \& LONKA, K. (2013). Experiences of disengagement A study of doctoral students in the behavioral sciences. International Journal of Doctoral Studies, 54(8), 61-81.

WIEGEROVÁ, A. (2016). The careers of young Czech University Teachers in the Field of Pedagogy. Zlín: UTB.

WIEGEROVÁ, A. (2017). Career Plans of Novice University Teachers: The Research Perspective. Acta Technologica Dubnicae, 7(1), 9-26. DOI: 10.1515/atd-20170001.

WHITE, L. (1949). The Science of Culture: A study of man and civilization. New York: Grove Press.

Zákon o vysokých školách 137/2016 Sb.

\section{Contact}

assoc. prof. Adriana Wiegerová, PhD.

Department of School Education

Faculty of Humanities

Tomas Bata University in Zlin

Štefánikova 5670

76001 Zlín, Czech Republic

wiegerova@utb.cz 